\title{
Human-specific dual regulations of FXR-activation for reduction of fatty liver using in vitro cell culture model
}

\author{
Teruo Miyazaki,, ${ }^{1, *}$ Akira Honda, ${ }^{1,2}$ Tadashi Ikegami, $^{2}$ Takashi lida $^{3}$ and Yasushi Matsuzaki ${ }^{2}$ \\ 'Joint Research Center and ${ }^{2}$ Department of Internal Medicine, Division of Gastroenterology and Hepatology, Tokyo Medical University Ibaraki Medical Center, \\ 3-20-1 Chuo, Ami, Inashiki, Ibaraki 300-0395, Japan \\ ${ }^{3}$ Department of Chemistry, College of Humanities and Sciences, Nihon University, 3-25-40 Sakurajosui, Setagaya-ku, Tokyo 156-8550, Japan
}

(Received 22 August, 2018; Accepted 19 September, 2018; Published online 28 November, 2018)

\begin{abstract}
Nuclear receptor farnesoid $X$ receptor activation inhibits fatty acid synthesis through the liver $X$ receptor- $\alpha$-sterol regulatory element binding protein-1c pathway universally in animals, but also has human-specific crosstalk with the peroxisome proliferator-activated receptor- $\alpha$. The effects of farnesoid $X$ receptor-ligands on both the synthesis and degradation of fatty liver through nuclear receptorrelated regulation were investigated in both human and murine hepatocytes. A fatty liver culture cell model was established using a synthetic liver $X$ receptor- $\alpha$-ligand (To901317) for both human and mouse non-neoplastic hepatocytes. The hepatocytes were exposed to natural or synthetic farnesoid $X$ receptor-ligands (bile acids, GW4064, obeticholic acid) together with or after To901317. Cellular triglyceride accumulation was significantly inhibited by the farnesoid $X$ receptor-ligands along with inhibition of lipogenic genes and up-regulation of farnesoid $X$ receptor-target small heterodimer partner in both human and mouse cells. The accumulated triglyceride was significantly degraded by the farnesoid $X$ receptor-ligands only in the human cells accompanied with the up-regulations of peroxisome proliferator-activated receptor- $\alpha$ and fatty acid $\beta$-oxidation. Farnesoid $X$ receptor-ligands can be therapeutic agents for treating human fatty liver through dual effects on inhibition of lipogenesis and on enhancement of lipolysis.
\end{abstract}

Key Words: fatty liver, nuclear receptor ligand, human-specific crosstalk, bile acids, lipolysis

- atty liver, also known as hepatic steatosis, is characterized by the deposition of triglyceride (TG) as lipid droplets in the cytoplasm of hepatocytes $(>55 \mathrm{mg} / \mathrm{g}$ of liver or $>5 \% \mathrm{TG}$ droplets in the liver). ${ }^{(1)}$ In addition to the various etiological causes, fatty liver is associated with diabetes mellitus and metabolic syndrome, and is the early stage of nonalcoholic fatty liver disease (NAFLD) that could progress to non-alcoholic steatohepatitis (NASH), liver cirrhosis, and cancer. The prevalence of diseases associated with fatty liver is increasing every year in the world, particularly in the developed countries. However, the early stage as fatty liver has not been received much attention for treatment because the state is not usually problematic due to lack of symptoms or pain. Furthermore, effective or useful therapies have been untested for this early manifestation.

In the liver, the genes involved in lipogenesis are essentially regulated by the sterol regulatory element factor binding protein1c (SREBP-1c) that is produced by the activation of liver $\mathrm{X}$ receptor- $\alpha$ (LXR $\alpha$ : NR1H3), a nuclear receptor for cholesterol derivatives, oxysterols (Fig. 1). ${ }^{(2-4)}$ The LXR $\alpha$-SREBP-1c pathway is directly inhibited by the atypical nuclear receptor small heterodimer partner (SHP; NR0B2) that is a target of the farnesoid X receptor (FXR; NR1H4). ${ }^{(5,6)}$
FXR, a member of the nuclear hormone receptor superfamily and a bile acid-responsive transcription factor, plays key roles not only in the regulation of bile acid synthesis and enterohepatic recirculation but also in both lipid and glucose metabolism. ${ }^{(7)}$ FXR-ligands have recently been the focus as the molecular target of pharmacological therapies for hepatobiliary ${ }^{(8-10)}$ and gastrointestinal diseases. ${ }^{(11)}$ Obeticholic acid ( $6 \alpha$-ethyl derivative of chenodeoxycholic acid, OCA ${ }^{(12,13)}$ ), a first-in-class selective FXRligand, has been evaluated in clinical trials of the patients with type II diabetes mellitus, NASH, and primary biliary cholangitis (PBC). ${ }^{(14-18)}$ These clinical studies demonstrated the excellent effectiveness of OCA treatment on cholestasis, insulin sensitivity, inflammation, and fibrosis in these patients. In addition, oral OCA administration improved hepatic steatosis in patients with noncirrhotic, non-alcoholic steatohepatitis in one clinical trial, ${ }^{(19)}$ and this effect was likely due to inhibition of lipogenesis through the FXR-SHP-SREBP-1c cascade (Fig. 1). ${ }^{(5,6)}$ However, there are no studies on the expression of SREBP-1c-regulated lipogenic genes in the liver tissues of the patients treated with the FXR-ligand.

In the studies on various rodent models including Zucker $(f a / f a)$ rats, ${ }^{(20)} \mathrm{ApoE}^{-/-}$mice, ${ }^{(21)}$ LDL receptor ${ }^{-/-}$mice, ${ }^{(22)}$ and obese $o b / o b$ mice, ${ }^{(23)}$ the elevated mRNA expression of the essential gene transcriptional factors in lipogenesis, including SREBP-1c and its target genes [acetyl-CoA carboxylase-1 (ACC-1), fatty acid synthase (FAS), malic enzyme, stearoyl-CoA desaturase-1 (SCD-1), and etc.] as well as a gluconeogenetic enzyme (phosphoenolpyruvate carboxykinases) in the liver tissues were decreased by OCA and other synthetic FXR-ligands, GW4064 and WAY-362450, accompanied with decreased hepatic TG levels. Furthermore, steatosis was reduced by OCA or GW4064. ${ }^{(24)}$ Therefore, the inhibitory effects of FXR-ligands on the hepatic steatosis in animal models are associated with decreased lipogenesis through the FXR-SHP-SREBP-1c cascade.

Likewise, the FXR-SHP-SREBP1c cascade is the mechanism of the attenuation of steatosis in the patients of the FXR-ligand treatment. However, there is a possibility that the improvement in steatosis by FXR-ligands are due to not only to inhibition of lipogenesis but also to enhancement of lipolysis, because there is molecular crosstalk between the FXR and peroxisome proliferatoractivated receptor- $\alpha$ (PPAR $\alpha$; NR1C1) (Fig. 1). PPAR $\alpha$ is highly expressed in the liver and is a principal lipid catabolism regulator in fatty acid transport and oxidation. Recent study showed that the PPAR $\alpha$ activation could improve hepatic steatosis by promoting of fat oxidation together with the inhibiting of lipogenesis through SREBP1c activation in the soy isoflavone-treated high fat diet

*To whom correspondence should be addressed. E-mail: teruom@tokyo-med.ac.jp 


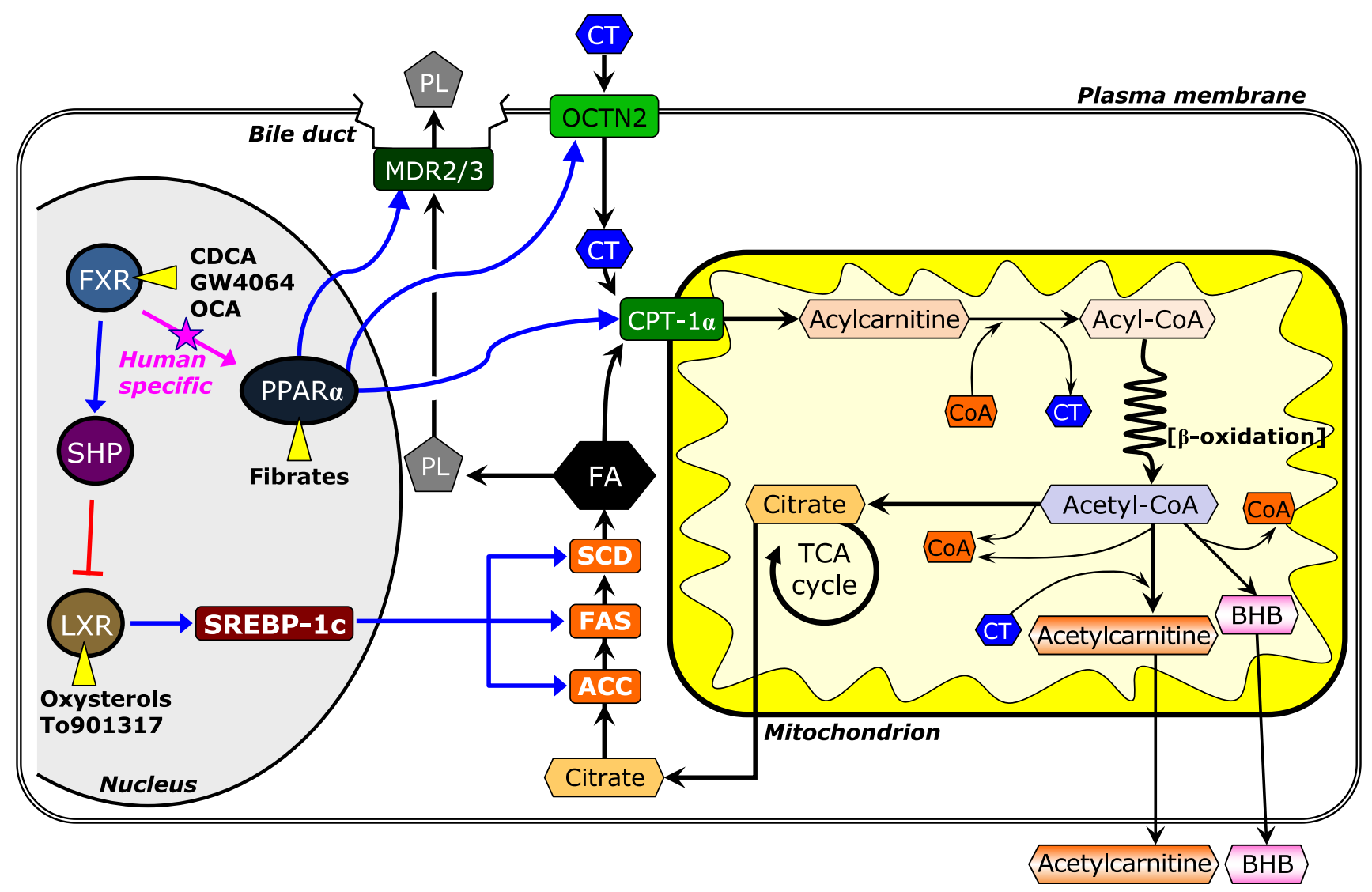

Fig. 1. Regulations of fatty acid metabolism, including synthesis, degradation, and secretion through nuclear receptors in hepatocytes. LXR $\alpha$ activated by natural ligand oxysterols and synthetic ligands induces the transcriptional factor SREBP-1C, and consequently, fatty acid biosynthesis from citrate is increased due to up-regulated gene expressions of fatty acid synthesis enzymes (ACC-1, FAS, and SCD-1). FXR activation promotes multilaterally the decrease of fatty acid levels through the inhibition of biosynthesis, and the enhancements of degradation and excretion of fatty acids. FXR activated by natural ligand bile acids and synthetic ligands inhibits SREBP-1c via up-regulation of SHP. The activated FXR also enhances nuclear receptor PPAR $\alpha$ that can be activated by natural ligand fatty acids and synthetic ligand. The activated PPAR $\alpha$ increases its target gene expressions (OCTN2 and CPT-1 $\alpha$ ). This crosstalk of FXR and PPAR $\alpha$ limits to humans. In addition, activated PPAR $\alpha$ also enhances the excretion of fatty acids as phospholipids (PL) into the bile via up-regulation of the gene expression of MDR protein.

NAFLD model rats. ${ }^{(25)}$ It is up-regulated by natural ligands, fatty acids, and synthetic ligands, such as fibrates. ${ }^{(26,27)}$ Therefore, FXRligand treatment is suggested to activate the PPAR $\alpha$-regulated lipolysis in fatty liver. Noteworthy, the crosstalk between the FXR and PPAR $\alpha$ is human-specific because of the presence of an FXR response element in the PPAR $\alpha$ promoter $(\alpha-$ FXR response element) that is present in humans, but not in rodents. ${ }^{(28)}$ Therefore, the effect of an FXR-ligand on PPAR $\alpha$-regulated gene expressions in the liver cannot be evaluated in the animal models, and has not been studied in the steatotic livers of the patients in the clinical trials.

Therefore, culture cell model of fatty liver as an experimental tool is useful to better understand the gene responses in both lipogenesis and lipolysis of the liver under FXR-ligand treatment. As fatty liver models of culture cell, the treatment of fatty acids has been well established in the primary hepatocytes and cell lines. ${ }^{(29,30)}$ However, the fatty acids-induced fatty liver models are unsuitable for the evaluation of these points, because fatty acids are natural PPAR $\alpha$ ligand. Furthermore, there are some restrictions and inconveniences in the primary hepatocytes on the limited and erratic supply, the significant inter-individual variability in the gene expression, and the culture duration and maintenance. The present study firstly attempted to establish a novel hepatic steatosis culture cell model for both human and mouse using nonmalignant hepatic cell lines treated with natural and synthetic
LXR $\alpha$ ligand (oxysterols, ${ }^{(31)}$ To901317(32) . Then, the effects of FXR-activation on lipogenesis and on lipolysis were compared between human and mouse in the newly established fatty liver culture cell model using natural and synthetic ligands (bile acids, GW4064, OCA).

\section{Materials and Methods}

Chemicals. Ursodeoxycholic acid (UDCA), chenodeoxy-

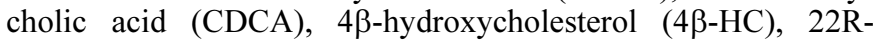
hydroxycholesterol (22R-HC), 25-hydroxycholesterol (25-HC), and 24S,25-epoxycholesterol (24S,25-EC) were purchased from Steraloids (Wilton, NH). To901317 $\{N$-(2,2,2-trifluoro-ethyl)- $N$ [4-(2,2,2-tri-fluoro-1-hydroxy-1-trifluoromethyl-ethyl)-phenyl]benzenesulfonamide\}, acetyl-L-carnitine $\mathrm{HCl}$, and sodium $\mathrm{D}-\beta$ hydroxybutyrate (BHB) were purchased from Sigma-Aldrich Chemical Co. (St. Louis, MO), and GW4064 (3-[2-[2-Chloro4[[3-3(2,6-dichlorophenyl)-5-(1-methylethyl)-4-isoxazolyl]methoxy] phenyl] ethenyl]benzoic acid) were purchased from Tocris Cookson Inc. (Ellisville, MO). Acetyl-L- $\left[{ }^{2} \mathrm{H}_{3}\right]$ carnitine $\mathrm{HCl}$ was purchased from $\mathrm{C} / \mathrm{D} / \mathrm{N}$ Isotopes Inc. (Quebec, Canada). Sodium DL-BHB${ }^{13} \mathrm{C}_{4}$ was obtained from Taiyo Nippon Sanso Co. (Tokyo, Japan), and 2-pyridinemethanol and 2-methyl-6-nitrobenzoic anhydride were obtained from Tokyo Kasei Kogyo (Tokyo, Japan). L-carnitine and 4-dimethylaminopyridine were obtained from Wako Pure 
Chemical Industries (Osaka, Japan). Fenofibric acid (FA) was supplied by ASKA Pharmaceutical. Co., Ltd. (Tokyo, Japan). OCA was a kind gift from Dr. Pelliciari R. (University of Bologna, Bologna, Italy), and from Dr. Hofmann A. (University of California, Berkeley, CA). These chemical reagents except for the bile acids were dissolved in ethanol and added to medium at 1:100 dilution. Additional reagents and solvents were of analytical grade.

Cultured hepatocytes. Non-tumor cultured hepatocyte cell lines and primary cultured hepatocytes of mouse and human were used for experimental steatosis culture model. AML12 cells, a differentiated, non-transformed cell line that was derived from transforming growth factor $\alpha$ over-expressing transgenic mice (ATCC, Manassas, VA), ${ }^{(33)}$ were cultured in a 1:1 mixture of Dulbecco's modified Eagle's medium (DMEM) and Ham's F12 medium (DMEM/F12, Invitrogen Japan KK, Tokyo, Japan) containing $3.151 \mathrm{~g} / \mathrm{L}$ glucose, supplemented with Insulin-TransferrinSelenium-X (ITS, final concentration; $5 \mu \mathrm{g} / \mathrm{ml}$ in each, GIBCO $^{\mathbb{R}}$, Invitrogen), $40 \mathrm{ng} / \mathrm{ml}$ dexamethasone (BioVision, Inc., Mountain View, CA), and 10\% fetal bovine serum (FBS). Fa2N-4 cells, a human cell line immortalized by transfection with SV40 large T antigen (MultiCell Technologies Inc., Woonsocket, RI), ${ }^{(34)}$ were cultured in DMEM containing $4.5 \mathrm{~g} / \mathrm{L}$ glucose, with $10 \%$ FBS. Primary hepatocytes of mouse and human (Life Technologies ${ }^{\mathrm{TM}}$, Thermo Fischer Scientific Inc., Rockford, IL) were seeded on a collagen coated 24 -well plate as $3.0 \times 10^{5}$ cells/well in the plating medium [Williams' Medium (Invitrogen Japan KK) with the Hepatocyte Plating Supplement Pack (CM3000, Invitrogen Japan $\mathrm{KK}$ ) containing $5 \% \mathrm{FBS}, 0.1 \mu \mathrm{M}$ dexamethasone, $100 \mathrm{U} / \mathrm{ml}$ Penicillin/Streptmycin, $4 \mu \mathrm{g} / \mathrm{ml}$ human recombinant insulin, $2 \mathrm{mM}$ GlutamaxTM, $15 \mathrm{mM}$ HEPES]. After $6 \mathrm{~h}$, the medium was changed to the maintenance medium [Williams' Medium with the Cell Maintenance Supplement Pack (CM4000, Invitrogen Japan KK) containing $0.1 \mu \mathrm{M}$ dexamethasone, $50 \mathrm{U} / \mathrm{ml}$ Penicillin/Streptmycin, $6.25 \mu \mathrm{g} / \mathrm{ml}$ ITS, $1.25 \mathrm{mg} / \mathrm{ml}$ bovine serum albumin (BSA), $5.35 \mu \mathrm{g} / \mathrm{ml}$ linoleic acid, $2 \mathrm{mM}$ GlutamaxTM, $15 \mathrm{mM}$ HEPES]. After overnight culture, the primary hepatocytes were used for following experiments. All cells were incubated at $37^{\circ} \mathrm{C}$ in a humidified incubator containing $5 \% \mathrm{CO}_{2}$ and $95 \%$ air.

Generation of a steatosis model using non-tumor hepatocyte cell lines. Sub-confluent AML12 cells were exposed to either $10 \mu \mathrm{M}$ oxysterols (4 $\beta$-HC, 22R-HC, 25-HC or 24S,25-EC) or $1 \mu \mathrm{M}$ To901317, for 4 days. Each reagent was dissolved in ethanol and was added to fresh medium at 100 -fold dilution (1\%). Although $1 \%$ ethanol had no detectable influence on cell growth, the same concentration of ethanol was also added to control wells. In addition, the effectiveness of To901317 on lipogenesis was evaluated in dose- and time-dependent manners. The Fa2N-4 cells were also exposed to $1 \mu \mathrm{M}$ To901317 for 4 days. After the exposure period, the cells were collected and used for analyses of lipogenesisrelated gene expression and intracellular TG accumulation.

Experimental protocols. AML12 and Fa2N4 cells were seeded in 6-well plates and cultured until sub-confluent to investigate the effect of FXR-ligands on the lipogenesis. Then, the cells were exposed to each FXR-ligand together with $1 \mu \mathrm{M}$ To901317 for 4 days. The used FXR-ligands used for the study were $50 \mu \mathrm{M}$ UDCA, $50 \mu \mathrm{M}$ CDCA, $1 \mu \mathrm{M}$ GW4064, and $1 \mu \mathrm{M}$ OCA. After exposure for 4 days, gene expression for lipogenesis and intracellular TG levels were analyzed by the methods discussed below. For the evaluation of effectiveness of FXR-ligands on TG catabolism, the cell lines were first exposed to $1 \mu \mathrm{M}$ To901317 for 4 days. Then, the cells were washed twice with PBS and cultured with each FXR-ligand or a synthetic PPAR $\alpha$-ligand ( $1 \mu \mathrm{M} \mathrm{FA})$ for 3 days. Then, gene expression for TG catabolism and intracellular TG levels were assayed.

The primary hepatocytes of mouse and human were exposed to $1 \mu \mathrm{M}$ To901317 with $1 \mu \mathrm{M}$ GW4064 or $1 \mu \mathrm{M}$ OCA for $24 \mathrm{~h}$.

RNA measurement. Total RNA was extracted from the cells using the RNeasy Plus Mini Kit (QIAGEN K.K., Tokyo, Japan).
Reverse transcription was performed on $0.5 \sim 1.0 \mu \mathrm{g}$ of total RNA using the PrimeScript ${ }^{\mathbb{B}}$ RT reagent Kit (TAKARA Bio. Inc. Shiga, Japan). Real-time quantitative PCR was performed on cDNA aliquots with the FastStart DNA Master SYBR Green I and the LightCycler (Roche Diagnostics, Mannheim, Germany). The sequences of the oligonucleotide primer pairs used to amplify the mRNA in the mouse and human cells are shown in Table 1. PCR amplification began with a $10 \mathrm{~min}$ pre-incubation step at $95^{\circ} \mathrm{C}$, followed by 40 cycles of denaturation at $95^{\circ} \mathrm{C}$ for $10 \mathrm{~s}$, annealing at $62^{\circ} \mathrm{C}$ for $10 \mathrm{~s}$, and elongation at $72^{\circ} \mathrm{C}$ (Table 1$)$. The relative concentration of PCR product derived from the target gene was calculated using the LightCycler System software. A standard curve for each run was constructed by plotting the crossover point against the log concentration. The concentration of target molecules in each sample was then calculated automatically by reference to this curve $(r=-1.00)$, and the results were standardized to the expression of $\beta$-actin. The specificity of each PCR product was assessed by melting curve analysis.

TG assays. Cellular TG levels were measured using the Triglyceride E-Test Wako (Wako Pure Chemical Industries). After each experiment, the cells were washed twice with PBS, and then, collected into a $0.5 \mathrm{ml}$ tube with $100 \mu \mathrm{l}$ PBS. The collected cells were sonicated, and used for the assay and for measurement of total protein using the Pierce ${ }^{\circledR}$ BCA Protein Assay Kit (Thermo Fischer Scientific Inc.). Cellular TG concentration was expressed as per total protein level. The cellular TG was also stained with oil-red using the Lipid Assay Kit (Primary Cell Co., Ltd., Hokkaido, Japan). For histology, the cells were fixed with $4 \%$ paraformaldehyde overnight, and the cellular TG was stained with oil-red following two washes with PBS.

$\boldsymbol{\beta}$-Oxidation activity. AML12 and $\mathrm{Fa} 2 \mathrm{~N}-4$ cells seeded in 6 -well plates were cultured in the growth media mentioned above. When the cells were confluent, the media were replaced with a specific medium to derive the $\beta$-oxidation reaction: serum-free DMEM containing $1.0 \mathrm{~g} / \mathrm{L}$ glucose, $1 \mathrm{mM}$ L-carnitine, and $200 \mu \mathrm{M}$ palmitic acid with $10 \%(w / v)$ fatty-free BSA. For the $\beta$-oxidationderivative medium, either $50 \mu \mathrm{M}$ UDCA, $50 \mu \mathrm{M}$ CDCA, $1 \mu \mathrm{M}$ GW4064, $1 \mu \mathrm{M}$ OCA, or $1 \mu \mathrm{M}$ FA was also added. After incubation for $4 \mathrm{~h}$, the culture media were collected to measure the concentrations of acetylcarnitine and BHB that are metabolites excreted from the cells due to $\beta$-oxidation. ${ }^{(35)}$

$\beta$-Hydroxybutyrate concentration in the culture medium was assayed as described previously. ${ }^{(36)}$ Briefly, $5 \mu \mathrm{l}$ of the medium was mixed with $100 \mathrm{ng}$ of sodium DL-BHB- ${ }^{13} \mathrm{C}_{4}$ in $100 \mu \mathrm{l}$ of acetonitrile-water $(19: 1, v / v)$, and deproteinized liquid phase was collected and evaporated to dryness. After derivatization of BHB into 2-pyridinemethanol esters, an aliquot was assayed by the HPLC-electrospray ionization (ESI)-MS/MS system.

Acetylcarnitine in the medium was quantified by the HPLCESI-MS/MS system as described previously ${ }^{(37)}$ with some modifications of a method reported by Ghoshal et al. ${ }^{(38)}$ Ten $\mu l$ of the medium was mixed with $5 \mathrm{ng}$ of acetyl- $\mathrm{L}-\left[{ }^{2} \mathrm{H}_{3}\right]$ carnitine $\mathrm{HCl}$ in $100 \mu \mathrm{l}$ of acetonitrile-water $(19: 1, v / v)$, and the deproteinized liquid phase was collected and evaporated to dryness. The residue was redissolved in $0.1 \%$ formic acid solution, and an aliquot was analyzed by the HPLC-ESI-MS/MS system. The chromatographic separation was performed using a Hypersil GOLD a Q column $\left(150 \times 2.1 \mathrm{~mm}, 3 \mu \mathrm{m}\right.$, Thermo Fisher Scientific) at $40^{\circ} \mathrm{C}$. The mobile phase was methanol-water $(1: 9, v / v)$ containing $0.1 \%$ formic acid at a flow rate of $200 \mu \mathrm{l} / \mathrm{min}$. The MS/MS conditions were as follows: spray voltage, $3,000 \mathrm{~V}$; vaporizer temperature, $450^{\circ} \mathrm{C}$; sheath gas (nitrogen) pressure, $50 \mathrm{psi}$; auxiliary gas (nitrogen) flow, 15 arbitrary units; ion transfer capillary temperature, $220^{\circ} \mathrm{C}$; collision gas (argon) pressure, $1.0 \mathrm{mT}$ Torr; collision energy, $15 \mathrm{~V}$; ion polarity, positive; and SRM, $m / z 204 \mathrm{~g} \mathrm{~m} / z 85$ for the acetylcarnitine and $\mathrm{m} / \mathrm{z} 207 \mathrm{~g} \mathrm{~m} / \mathrm{z} 85$ for the $\left[{ }^{2} \mathrm{H}_{3}\right]$ variant.

Cell viability. The influence of chemical reagents used on the cell viability was evaluated by the MTT assay. ${ }^{(39)}$ AML12 and 
Table 1. Conditions of quantitative real-time PCR and sequences of primers

\begin{tabular}{|c|c|c|c|c|c|}
\hline Gene name & Accession number & & Sequence & Product size & Elongation time \\
\hline Human & & & $\left(5^{\prime}-3^{\prime}\right)$ & (bp) & (s) \\
\hline \multirow{2}{*}{$\mathrm{ACC}-1$} & \multirow{2}{*}{ NM_198834 } & $\mathrm{F}$ & CAG AGA CTA CGT CCT CAA GCA A & \multirow{2}{*}{119} & \multirow{2}{*}{5} \\
\hline & & $\mathrm{R}$ & GTA TGA CTT CTG CTC GCT GA & & \\
\hline \multirow{2}{*}{ CPT-1 $1 \alpha$} & \multirow{2}{*}{ NM_001876 } & $\mathrm{F}$ & TGG AAC AGA GGC TGA AGT & \multirow{2}{*}{192} & \multirow{2}{*}{8} \\
\hline & & $\mathrm{R}$ & GGG TCT GGC TTG TTG ATA AT & & \\
\hline \multirow{2}{*}{ FAS } & \multirow{2}{*}{ NM_004104 } & $\mathrm{F}$ & CAC CCA AGG CCA AGT ACC AT & \multirow{2}{*}{119} & \multirow{2}{*}{5} \\
\hline & & $\mathrm{R}$ & GGA TAC TTT CCC GTC GCA TA & & \\
\hline \multirow{2}{*}{ MDR3 } & \multirow{2}{*}{ M23234 } & $\mathrm{F}$ & ATA GCT CAC GGA TCA GGT C & \multirow{2}{*}{183} & \multirow{2}{*}{8} \\
\hline & & $\mathrm{R}$ & AGC ACC CAA TCC TGA GTA G & & \\
\hline \multirow{2}{*}{ OCTN2 } & \multirow{2}{*}{ NM_003060 } & $\mathrm{F}$ & CCA GAT GCT AAG AGT CAA AGG AAT & \multirow{2}{*}{110} & \multirow{2}{*}{5} \\
\hline & & $\mathrm{R}$ & GTT AGA AGG CTG TGC TTT TAA GGA & & \\
\hline \multirow{2}{*}{$\operatorname{PPAR} \alpha$} & \multirow{2}{*}{ NM_001001928 } & $\mathrm{F}$ & CCA TCG GCG AGG ATA GTT C & \multirow{2}{*}{144} & \multirow{2}{*}{6} \\
\hline & & $\mathrm{R}$ & CGG GGA CCA CAG GAT AAG T & & \\
\hline \multirow{2}{*}{ SCD-1 } & $4 M 0105063$ & $\mathrm{~F}$ & CCG GGA GAA TAT CCT GGT TTC A & 107 & 5 \\
\hline & IVIVI_UUJU6s & $\mathrm{R}$ & TGA TGT GCC AGC GGT ACT CA & 107 & 5 \\
\hline SHP & NM 021969 & $\mathrm{F}$ & AGA CAG ACC CCA GCC CTC C & 170 & 7 \\
\hline SHF & IVIVI_ULIYOS & $\mathrm{R}$ & GCA CCT GCA GCA GGA GGC T & $1 / 0$ & I \\
\hline & & $\mathrm{F}$ & GCC CAG GTG ACT CAG CTA TT & & \\
\hline SREBP-1C & NM_004176 & $\mathrm{R}$ & GTC AGA GAG GCC CAC CAC TT & 245 & 10 \\
\hline & & $\mathrm{F}$ & ACT GGG ACG ACA TGG AGA AA & & \\
\hline$\beta$-actın & NIVI_OUT101 & $\mathrm{R}$ & ATA GCA CAG CCT GGA TAG CA & 189 & 8 \\
\hline Mouse & & & $\left(5^{\prime}-3 '\right)$ & (bp) & (s) \\
\hline$A C C-1$ & NM 198834 & $\mathrm{~F}$ & GCT GCT GGA GGA CTT CAT & 204 & 9 \\
\hline$A C C-1$ & IVIVI_1900د4 & $\mathrm{R}$ & AGA ATC GAC ACT GGC TGG & 204 & $y$ \\
\hline CPT- $1 \alpha$ & NM 013495 & $\mathrm{~F}$ & GGG AGA GAA TTT CAT CCA CT & 198 & 8 \\
\hline & & $\mathrm{R}$ & TGG TTT GTA TCA CTA GAG TCC A & 198 & 8 \\
\hline FAS & NM 004104 & $\mathrm{~F}$ & GGC CAC TAT ACT ACC CAA GA & 112 & 5 \\
\hline & & $\mathrm{R}$ & GAT TGT GAG CGG AAA AGT G & 112 & 3 \\
\hline PPAR $\alpha$ & NM 011144 & $\mathrm{~F}$ & CGA CCT GAA AGA TTC GGA AAC & 184 & 8 \\
\hline PPAR $\alpha$ & IVIVI_OIII44 & $\mathrm{R}$ & AAG CGT CTT CTC GGC CAT A & 184 & $\gamma$ \\
\hline MDR? & NM 008830 & $\mathrm{~F}$ & ACC AGT GTC TTT TCT GAA GGT C & 166 & 7 \\
\hline IVIDR2 & NIVI_008ర30 & $\mathrm{R}$ & CTG CTT CAC TGC GTC ATC & 166 & 1 \\
\hline & & $\mathrm{F}$ & TAC CAT TGA CCA GAT GCT AAG & & 5 \\
\hline OCIN2 & NIM_011396 & $\mathrm{R}$ & TGT TAG AAG GCT GTG CTC TTT A & 120 & 5 \\
\hline SCD-1 & NM 009127 & $\mathrm{~F}$ & TG CTATCGGGGT GTTAATGA & 128 & 6 \\
\hline 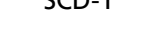 & IVIVI_UUYizi & $\mathrm{R}$ & TAA CCA TGC CAC AAG ACA & $1<0$ & 0 \\
\hline SHP & NM 011850 & $\mathrm{~F}$ & CAA GGA GTA TGC GTA CCT GA & 232 & 10 \\
\hline JiI & IVIVI_Utioso & $\mathrm{R}$ & ATC TCT TCT TCC GCC CTA TC & & 10 \\
\hline SRFBP-1C & NM 011480 & $\mathrm{~F}$ & CCA TTG ACA AGG CCA TGC & 162 & 7 \\
\hline SKEBP-IC & INIVI_UII & $\mathrm{R}$ & GGT CAT GTT GGA AAC CAC GC & 102 & 7 \\
\hline$\beta$-actin & $\times 03672$ & $\mathrm{~F}$ & CCT GTA TGC CTC TGG TCG TA & 260 & 11 \\
\hline$\beta$-actin & $x 036 / 2$ & $\mathrm{R}$ & AGA CTT CGA GCA GGA GAT GG & $\angle 60$ & 11 \\
\hline
\end{tabular}

ACC-1, acetyl-CoA carboxylase-1; CPT-I $\alpha$, carnitine palomitoyltransferase-l $\alpha$; FAS, fatty acid synthase; PPAR $\alpha$, peroxisome proliferator-activated receptor- $\alpha$; MDR, multidrug resistance protein; OCTN2, organic cation transporter 2; SCD-1, steatoryl-CoA desaturase-1; SHP, small heterodimer partner; SREBP-1C, sterol regulatory element binding protein-1c; F, forward primer; R, reverse primer; bp, base pair.

Fa2N-4 cells seeded on a 24-well plate were exposed to either $1 \mu \mathrm{M}$ each of To901317, GW4064, or OCA, or to $10-100 \mu \mathrm{M}$ each of UDCA and CDCA for $24 \mathrm{~h}$.

Statistical analysis. All presented data are the mean \pm SD from at least three independent experiments. Significant differences were determined by the unpaired student's $t$ test or one-way ANOVA post hoc Bonferonni's test for comparisons between two groups or among multiple groups, respectively. The statistical analyses were performed using Prism software (GraphPad Software, Inc., La Jolla, CA).

\section{Results}

Steatosis model of cultured hepatocytes treated with LXRo-ligand. In AML12 cells exposed to various types of oxysterol as natural LXR $\alpha$-ligand or a synthetic LXR $\alpha$-ligand To901313 for 4 days, markedly increase of intracellular TG accumulation evaluated by the oil-red stain assay was observed in exposing to 22R-HC, 25-HC, 24S,25-EC, and To901317 (Fig. 2A). In the quantification assay, intracellular TG levels were significantly increased in the cells exposed to 22R-HC, 24S,25-EC, and To901317 compared with that of the control (Fig. 2B). Cellular 

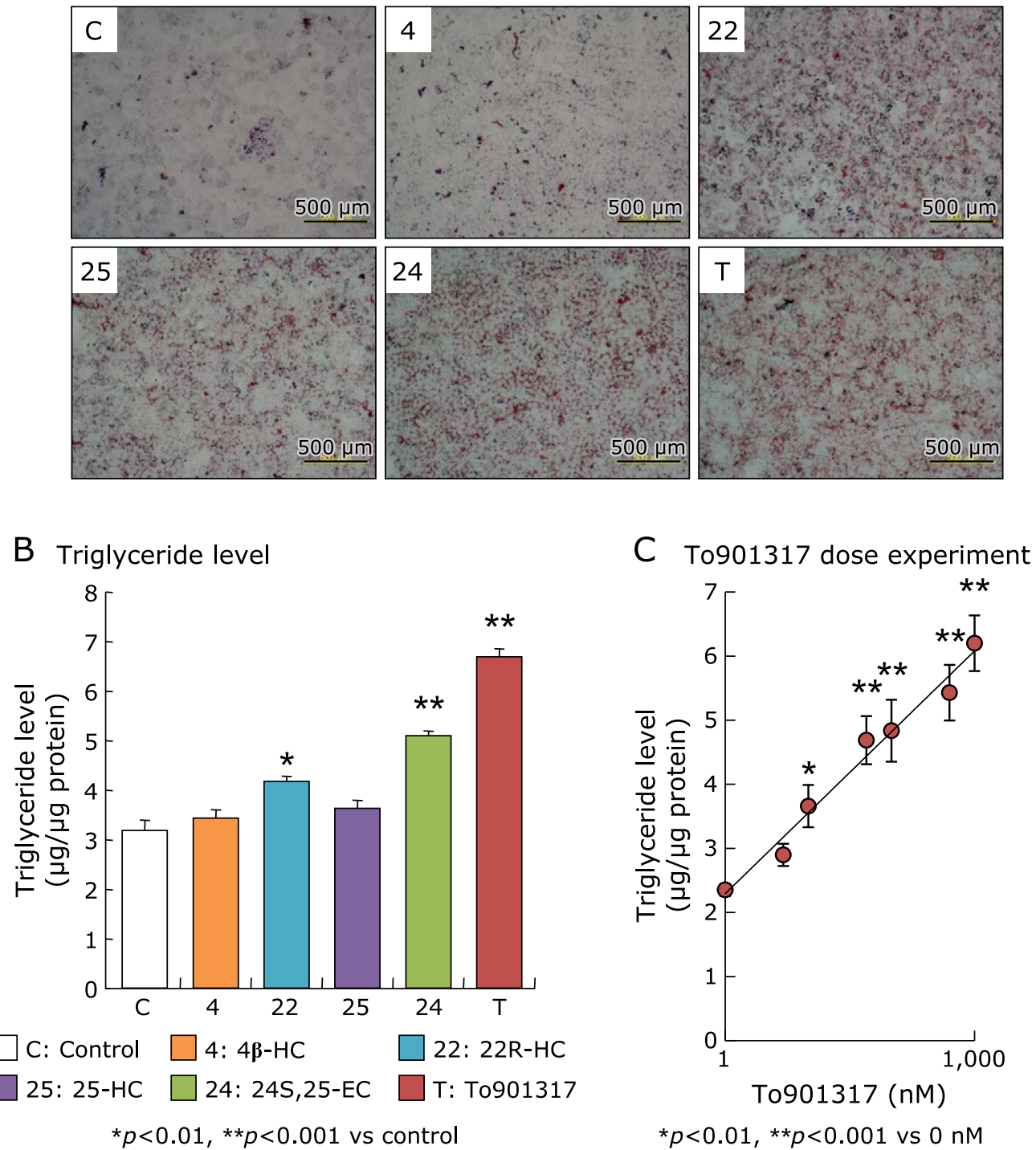

Fig. 2. Oil-red stain image (A) and quantified intracellular triglyceride level (B) in $A M L 12$ cell after the exposure of either $10 \mu M$ of oxysterols $(4 \beta-\mathrm{HC}, 22 \mathrm{R}-\mathrm{HC}, 25-\mathrm{HC}$, or 24S,25-EC) or $1 \mu \mathrm{M}$ of To901317 for 4 days. (C) shows triglyceride level in AML12 cell after exposure to various concentrations of To901317 $(0,10,25,50,100,500$, and 1,000 nM) for 4 days. Triglyceride level in the cells was measured by the triglyceride test kit Wako and expressed as per total protein level, and was also stained with oil-red. Data in the (B) and (C) are shown as the mean \pm SD. Statistical difference was carried out by one-way ANOVA Bonferroni's post hoc test.

TG level was increased in a dose-dependent manner up to $1 \mu \mathrm{M}$ To901317 that had the most potent ligand activity among the examined LXR $\alpha$-ligands (Fig. 2C).

In AML12 cells exposed to oxysterols or To901317 for 4 days, the mRNA levels of SREBP-1c and all examined SREBP-1c target genes (ACC-1, FAS and SCD-1) were significantly increased by $24 \mathrm{~S}, 25-\mathrm{EC}$ and To901317 treatments compared to those in the controls (Fig. 3A). In addition, 22R-HC treatment significantly up-regulated mRNA levels of ACC- 1 and FAS. Since the LXR $\alpha-$ activations were greater in To901317 than in the oxysterols in AML12 cells, To901317 was selected for further study of Fa2N-4 cells. Similar to AML12 cells, the mRNA levels of SREBP-1c and its target genes in the Fa2N-4 cells were significantly elevated by To901317 for 4 days (Fig. 3B).

Anti-lipogenic and pro-lipolytic effects of FXR-ligands.

Using the established steatosis cultured cell model with To901317, the effect of FXR-ligand treatment on the TG levels was compared between the mouse AML12 and human Fa2N-4 cells. After cotreatments of either natural FXR-ligands (UDCA and CDCA) or synthetic FXR-ligands (GW4064 and OCA) together with To901317 for 4 days, cellular TG level was significantly reduced in both AML12 and Fa2N-4 cells by cotreatment of CDCA, GW4064, and OCA, but not UDCA, compared to that in the To901317 alone (Fig. 4A).

To evaluate the lipolytic effects of FXR activation on accumulated TG level, both cell lines were treated with the natural and synthetic FXR-ligands as well as synthetic PPAR $\alpha$-ligand (FA) in the absence of To901317 for 3 days in the steatosis cell model with To901317 for 4 days. In AML12 cells, the accumulated TG level was unchanged by any FXR-ligands, but significantly reduced by FA (Fig. 4B). In contrast, cellular TG level in Fa2N-4 cells was significantly reduced by CDCA, GW4064, OCA, and FA (Fig. 4B). 

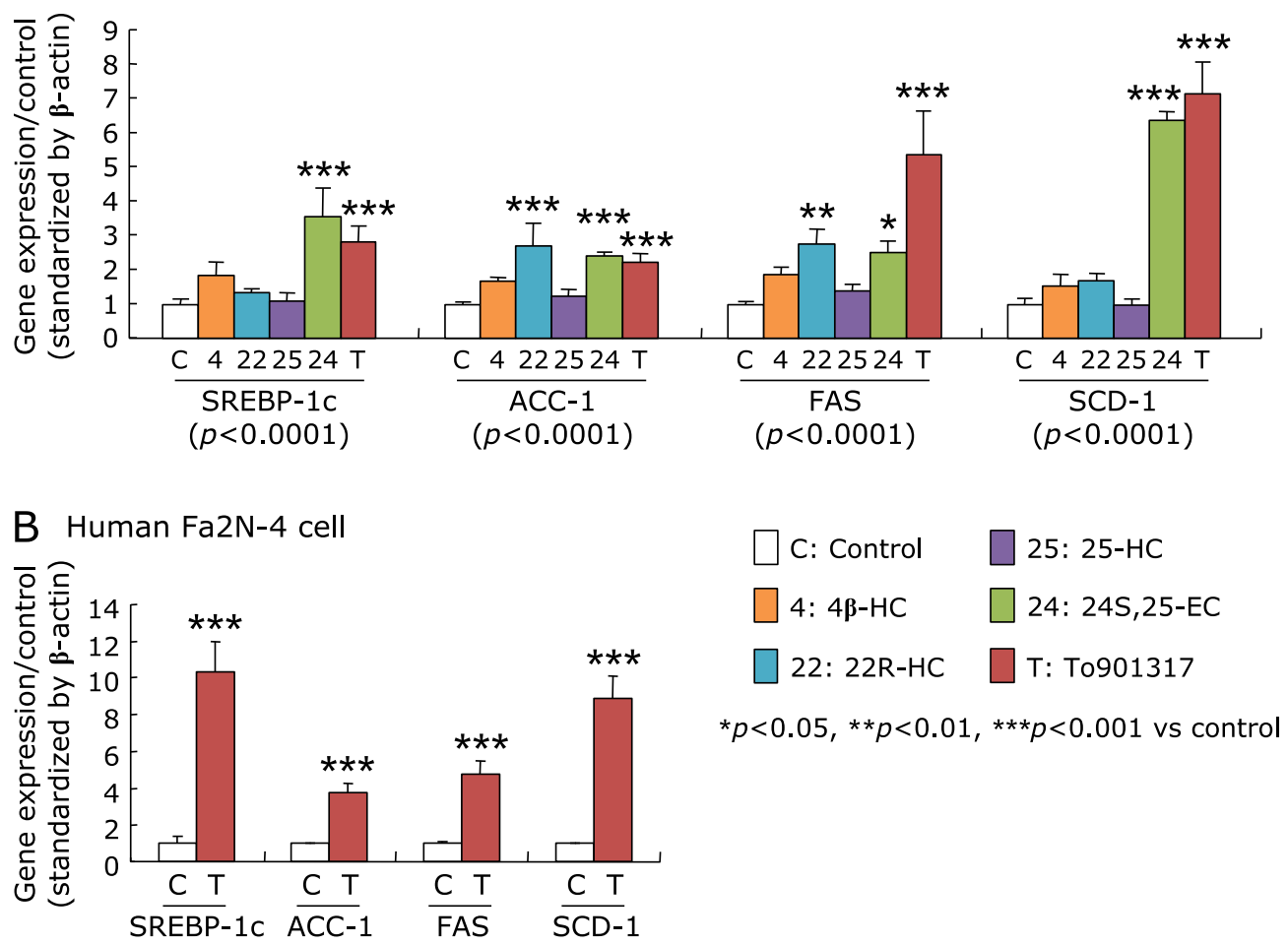

Fig. 3. The mRNA levels of SREBP-1c and its target genes in AML12 cells (A) and human Fa2N-4 cells (B), exposed to either natural or synthetic $\mathrm{LXR} \alpha$-ligands. AML12 cells were treated with either $10 \mu \mathrm{M}$ of each oxysterol or $1 \mu \mathrm{M}$ To901317, and Fa2N-4 cells were treated with or without $1 \mu \mathrm{M}$ To901317 for 4 days. The mRNA levels were measured by quantitative real-time PCR and expressed as the relative to control after standardization by $\beta$-actin. Data are shown as the mean \pm SD. Statistical differences were carried out by one-way ANOVA Bonferroni's post hoc test, or unpaired student's $t$ test. Values in the parenthesis of $(A)$ show $p$ values of one-way ANOVA test.

Effects of FXR-ligands on lipogenic and lipolytic gene expressions. In both AML12 and Fa2N-4 cells, SREBP-1c mRNA expression was significantly induced by To901317 treatment, but bile acids and synthetic FXR-ligands had no effect on the SREBP-1c mRNA level in the absence and the presence of To901317 (Fig. 5A and F). The mRNA levels of SREBP-1c target genes (ACC-1, FAS, SCD-1) were also significantly increased by To901317 treatment, and the gene inductions were significantly inhibited by CDCA, GW4064 and OCA in the both cell lines (Fig. 5B-D and G-I). On the other hand, the SHP mRNA level was significantly induced by CDCA, GW4064, and OCA in the both cell lines irrespective of the presence of To901317 (Fig. 5E and $\mathrm{J}$ ).

Similar to the cell lines, the mRNA levels of SREBP-1c and its target genes were significantly increased by To901317 treatment, and the significantly increases of the lipogenic genes were significantly inhibited by the cotreatments of synthetic FXRligands (GW4064 and OCA) in the primary hepatocytes of human and mouse, although the significantly inhibitions were not observed in FAS in mouse and ACC-1 in human (Fig. 6A-D and $\mathrm{F}-\mathrm{I})$. The SHP mRNA level was also significantly increased by the synthetic FXR-ligands in the both primary hepatocytes (Fig. 6E and J).

In AML12 cells, the mRNA levels of lipolytic genes including PPAR $\alpha$, carnitine palomitoyltransferase-I $\alpha$ (CPT-I $\alpha)$, and organic cation transporter 2 (OCTN2: SLC22A5) were significantly increased by only FA, but not the FXR-ligands, irrespective of the presence of To901317 (Fig. 7A-C). In contrast, the expression of lipolytic genes in $\mathrm{Fa} 2 \mathrm{~N}-4$ cells were significantly increased by CDCA, GW4064, and OCA as well as FA (Fig. 7E-G).
In AML12 cells, multidrug resistance protein (MDR: ABCB4) 2 mRNA level was significantly increased by CDCA, GW4064, and OCA irrespective of the presence of To901317, and by FA in presence of To901317 (Fig. 7D). In contrast, the up-regulation of MDR3 by FXR-ligands was observed in Fa2N-4 cells, but was much less than that in AML12 cells (Fig. 7H).

Effect of FXR-ligands on fatty acid catabolism. After incubation for $4 \mathrm{~h}$ without any treatments, the acetylcarnitine and BHB concentrations in the medium of the both AML12 and Fa2N4 cells were significantly elevated compared with that at baseline $(0 \mathrm{~h})$ (Fig. 8). In AML12 cells, there were no significant difference in acetylcarnitine and BHB concentrations between the FXRligand treatment conditions and untreated control conditions (Fig. 8A). In contrast, both acetylcarnitine and BHB concentrations in the medium of $\mathrm{Fa} 2 \mathrm{~N}-4$ cells were significantly increased by CDCA, GW4064, OCA, and FA (Fig. 8B).

Effects of FXR-ligands and To901317 on cell viability.

Cell viability of AML12 and Fa2N-4 cells was not affected by the treatments with To901317 and FXR-ligands except for high concentrations of CDCA (Fig. 9). Fa2N-4 cell viability was reduced at $50 \mu \mathrm{M}$ of CDCA, while that of AML12 cells was reduced at $100 \mu \mathrm{M}$.

\section{Discussion}

Fatty liver is a metabolic disease that is the early stage for NAFLD and NASH with a higher risk for progression to liver cirrhosis and cancer. Therefore, early treatment of fatty liver is recommended, if early interventions including exercise and diet control that are firstly recommended are not effective. However, 

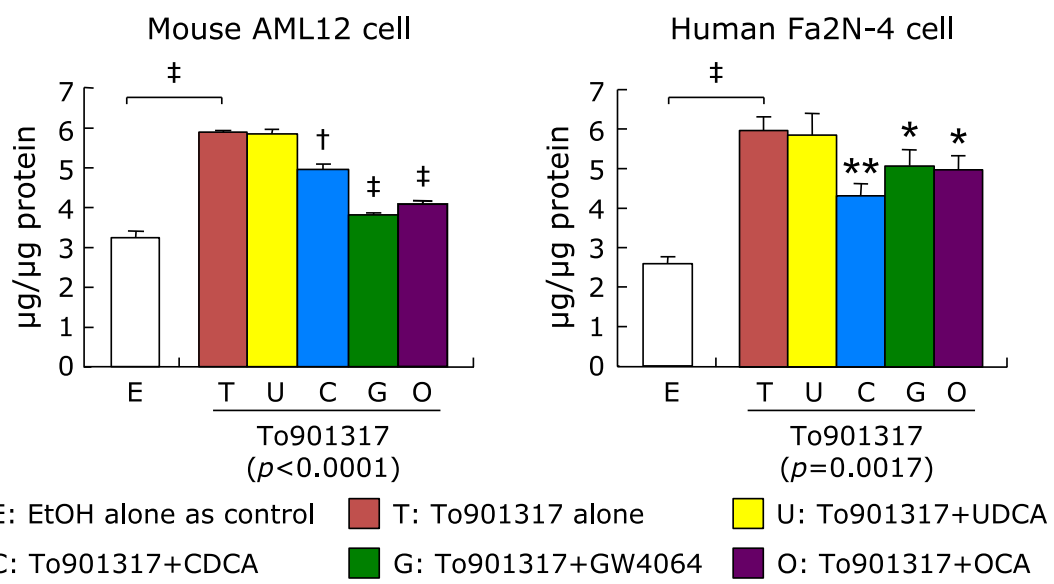

B FXR- or PPARa-ligand treatment following To901317

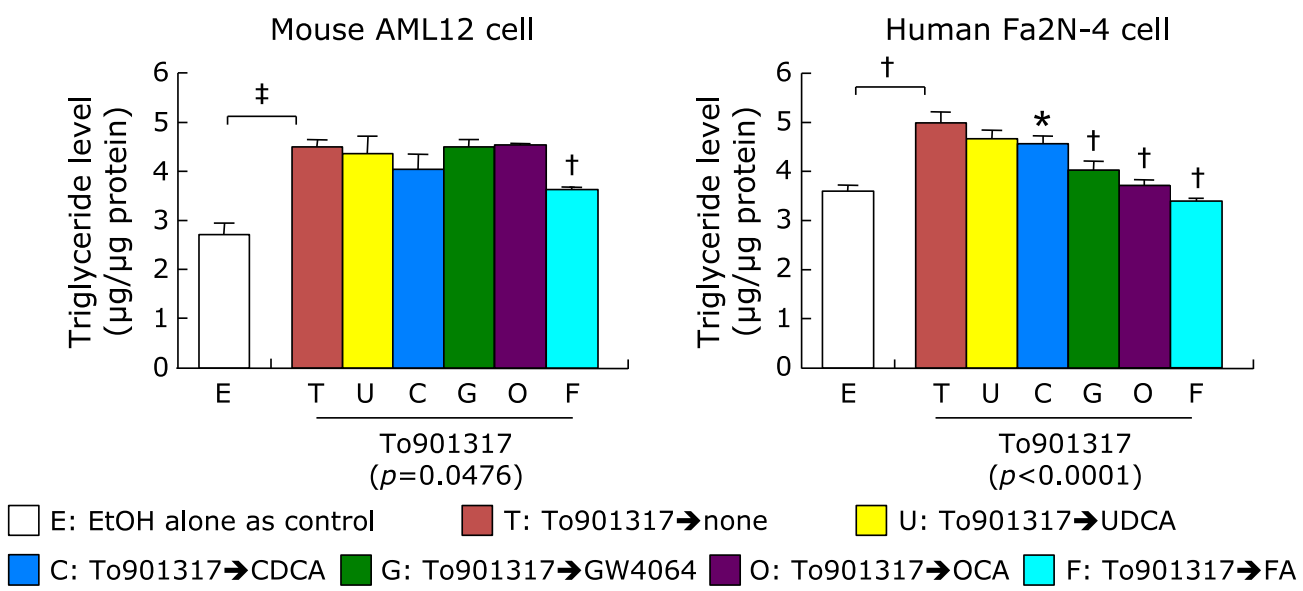

Fig. 4. The effects of FXR-ligands on synthesis and catabolism of triglyceride in the cells exposed to To901317. (A) AML12 and Fa2N-4 cells were exposed to $1 \mu \mathrm{M}$ of To901316 with or without $50 \mu \mathrm{M}$ of natural ligand bile acids; UDCA and CDCA, or $1 \mu \mathrm{M}$ of synthetic FXR-ligands; GW4064 and OCA, for 4 days. (B) AML and Fa2N4 cells were exposed to the natural FXR-ligand bile acids, synthetic FXR-ligands, or synthetic PPAR $\alpha$-ligand; FA, for 3 days following To901316 treatment for 4 days. Triglyceride level was expressed as the concentration per total protein level. Data are shown as the mean \pm SD. Statistical differences were analyzed by unpaired Student's $t$ test between the control and To901317 alone or one-way ANOVA Bonferroni's post hoc test between the To901317 alone and other ligand-treated conditions. ${ }^{*} p<0.05,{ }^{* *} p<0.01,{ }^{\dagger} p<0.001,{ }^{\ddagger} p<0.0001$. Values in the parenthesis under graph show $p$ values of one-way ANOVA test.

effective therapeutic agent for fatty liver remains to be still established. FXR ligands have been reported to improve hepatic steatosis as well as cholestasis, hepatic inflammation and fibrosis, and insulin resistance through inhibition of lipogenesis and gluconeogenesis in rodent models. ${ }^{(6,20,21,23)}$ The present study demonstrated that FXR activation by the natural ligand, CDCA, and by synthetic ligands, OCA and GW4064, significantly attenuated TG accumulation in a human fatty liver model through stimulation of the FXR-PPAR $\alpha$ pathway. Furthermore, in addition to the FXR-SHP-SREBP-1c cascade, these FXR-ligand treatments significantly inhibited SREBP-1c-related lipogenesis, but did not activate PPAR $\alpha$-related catabolism in the mouse fatty liver model. Therefore, the FXR-ligands could be an effective therapeutic agent for fatty liver by affecting both lipid synthesis and degradation, in addition to the clinical benefits for the patients with PBC, NASH, and diabetes mellitus. ${ }^{(14-17)}$

An evaluation using human, but not animal cells, were needed to clarify the human-specific dual mechanisms in lipid metabolism through FXR-activation. The present study could establish the steatosis model in non-malignant cell lines derived from human
(Fa2N-4) and mouse (AML12) livers by incubation with both natural and synthetic LXR $\alpha$-ligands along with the induction of lipogenesis-related genes. In particular, the synthetic LXR $\alpha$ ligand To901317 had more effective on the lipogenesis in a dosedependent manner. In the To901317-induced lipogenesis phase of the steatosis model in both the human and mouse cell lines, the TG accumulation was significantly suppressed by the cotreatments of FXR-ligands in accompany with the FXR-LXR $\alpha$-SREBP-1c cascade.

Present study also confirmed that there were similar gene responses to $\mathrm{LXR} \alpha$ and FXR activations in the lipogenesis phase between the non-tumor hepatic cell lines and the primary hepatocytes in both mouse and human. The lipogenesis-related genes were significantly increased by To901317, and the significant increases of the genes were significantly inhibited by the cotreatments of synthetic FXR-ligands in the primary hepatocytes of both human and mouse. In addition, the SHP mRNA expression was significantly increased by the synthetic FXR-ligands in the primary hepatocytes. So, we had also attempted to establish the fatty liver model using the primary hepatocytes. In the studies 

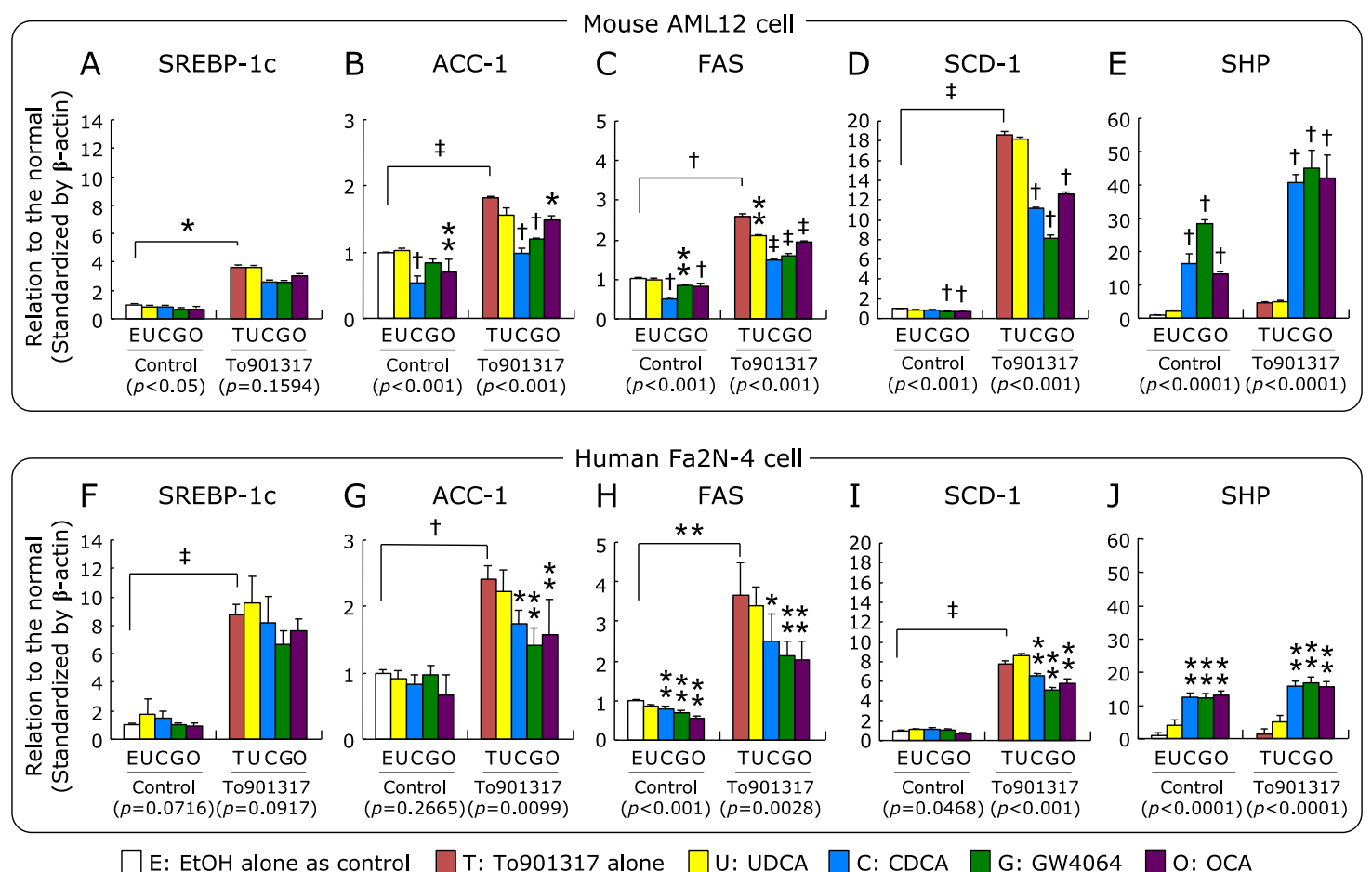

Fig. 5. The mRNA levels of lipogenic genes; SREBP-1C (A, F), ACC-1 (B, G), FAS (C, H), SCD-1 (D, I), SHP (E, J), in AML12 and Fa2N-4 cells treated with synthetic LXR $\alpha$ - and FXR-ligands. Both cell lines were exposed to the various types of natural and synthetic FXR-ligand (50 $\mu$ M UDCA, $50 \mu M$ CDCA, $1 \mu \mathrm{M}$ GW4064, $1 \mu \mathrm{M}$ OCA) and synthetic PPAR $\alpha$-ligand (1 $\mu \mathrm{M} \mathrm{FA})$ with or without $1 \mu \mathrm{M}$ To901317 for 4 days. The mRNA levels are expressed as relative to the control following standardization by $\beta$-actin, and are shown as the mean \pm SD. ${ }^{*} p<0.05,{ }^{*} p<0.01,{ }^{\dagger} p<0.001$ and ${ }^{\ddagger} p<0.0001$ shown on the column vs the respective control condition by one-way ANOVA Dunnett's post hoc analysis, and values in the parenthesis under graph show $p$ values of one-way ANOVA test. The significant difference between the control and To901317 alone was analyzed by unpaired Student's $t$ test.

using the cell lines, the lipogenesis and lipolysis phases needed the long period culture for 4 and additional 3 days, respectively. Because the primary cultured hepatocytes were hardly cultured for such long periods, it is likely to be difficult to generate the steatosis model by the LXR $\alpha$-ligands.

Generally, most studies in lipid metabolism have used experimental animals induced by feeding either high fat or calorie diets, or as transgenic models $(o b / o b, f a / f a) .{ }^{(40)}$ Data from the animal models are very valuable, but there are some species difference in lipid metabolism between humans and rodents. Furthermore, fatty acids are usually used to induce TG accumulation in culture hepatocytes, ${ }^{(29,30)}$ but the fatty acids-induced fatty liver model is unsuitable for the evaluation of the molecular crosstalk between FXR and PPAR $\alpha$ because fatty acids are natural PPAR $\alpha$ ligand. ${ }^{(26,27)}$ This cell culture model of fatty liver induced by LXR $\alpha$-ligands should be useful for evaluating the different mechanism of lipid metabolism for each species.

The different efficiencies of ligand-induced FXR-activation on the cellular TG level between the human and mouse cells should be based on the species difference in the lipid metabolism because of the human-specific FXR-PPAR $\alpha$ crosstalk reported by Pineda Torra et al. ${ }^{(28)}$ in addition to the universal FXR-SHP-SREBP-1c cascade. ${ }^{(6)}$ In the present study, the FXR-ligands (CDCA, OCA and GW4064) significantly increased the mRNA levels of PPAR $\alpha$ and its target gene CPT-I $\alpha$ in human cells in both the absence and presence of To901317, and these findings were in agreement with the study by Pineda Torra et al. ${ }^{(28)}$ Furthermore, the treatments with FXR-ligands in the human cells, but not in the mouse cells, significantly increased the mRNA level of the plasma membrane carnitine transporter OCTN2 that is also a target gene of PPAR $\alpha .{ }^{(41)}$ Both CPT- $1 \alpha$ and OCTN2 are associated with carnitine, an essential molecule for fatty acid oxidation. Indeed,
FXR-ligand treatment in the human cells significantly increased the extracellular excretion levels of acetylcarnitine and BHB that are metabolites of $\beta$-oxidation. ${ }^{(35)}$ Excess acetyl-CoA is metabolized into ketone bodies and/or acetylcarnitine when $\beta$-oxidation is up-regulated. Although OCA treatment has been previously reported to increase $\beta$-oxidation accompanied with the enhanced mRNA expressions of both PPAR $\alpha$ and PPAR $\gamma$ coavtivator- $1 \alpha$ in the skeletal muscle of Zucker rats, it is likely an indirect response through reduction of circulating free fatty acid levels because FXR is not expressed in skeletal muscle. ${ }^{(20)}$ The present study was the first to show that FXR-ligand treatment could directly enhance the $\beta$-oxidation reaction in human hepatocytes.

In addition, the present results showed that treatment with FXR-ligands could increase the mRNA expression of canalicular phospholipid flippase, MDR3 in human and MDR2 in mouse, to promote excretion of phospholipid into the bile, because the PPAR $\alpha$ target genes, MDR3/2, ${ }^{(42)}$ are also the target genes of FXR $^{(43,44)}$ Indeed, the significantly increases of MDR3/2 mRNA levels by GW4064 were observed in the human hepatoma cell line, ${ }^{(45)}$ and in both human hepatocytes and rodent liver. ${ }^{(46)}$ However, the enhancement of phospholipid excretion into the bile is not likely to contribute significantly to improvement of fatty liver, because accumulated TG levels in AML cell was not influenced by FXR-ligand treatment in the present study.

In the present study, the natural bile acid CDCA, but not UDCA, showed significant effects on the fatty acid metabolism in the both human and mouse cells. These results agree with the previous study that CDCA has the most potent activity as an FXR-ligand among the natural bile acids. UDCA does not have any effect as an FXR-ligand, because the FXR-ligand activity is specific and limited to the primary bile acids, and to a much less extent to the secondary bile acids. ${ }^{(47-49)}$ In clinical therapy, UDCA 

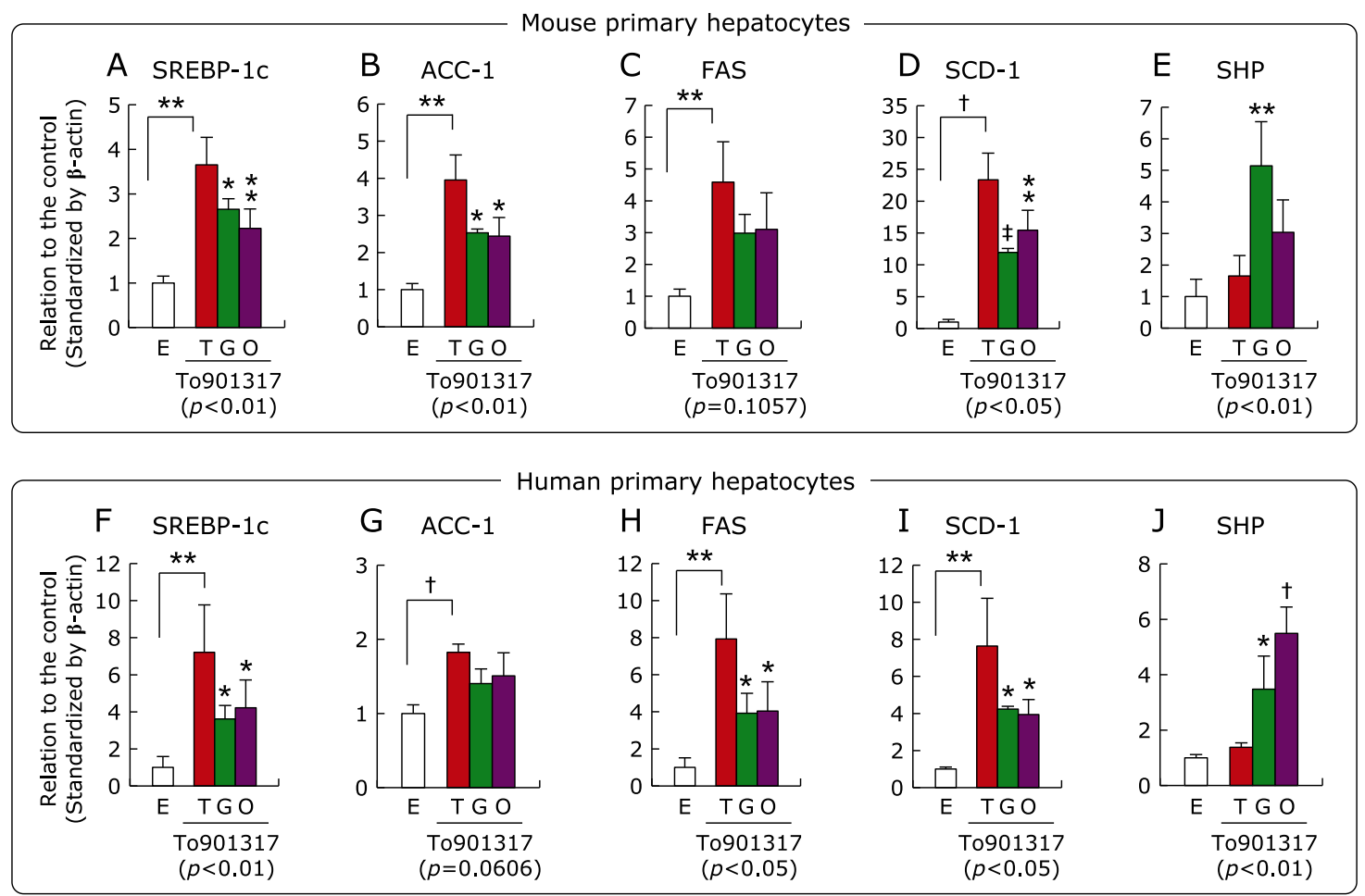

$\square$ E: EtOH alone as control $\square$ T: To901317 alone $\square$ G: GW4064 $\square$ O: OCA

Fig. 6. The mRNA levels of lipogenic genes; SREBP-1C (A, F), ACC-1 (B, G), FAS (C, H), SCD-1 (D, I), and SHP (E, J), in the primary hepatocytes of human and mouse treated with synthetic LXR $\alpha$ - and FXR-ligands. The primary hepatocytes were exposed to $1 \mu \mathrm{M}$ To901317 with or without $1 \mu \mathrm{M}$ GW4064 or $1 \mu \mathrm{M}$ OCA for $24 \mathrm{~h}$. The mRNA levels are expressed as relative to the control following standardization by $\beta$-actin. Data are shown as the mean \pm SD from quadruplicate experiments. ${ }^{*} p<0.05,{ }^{*} p<0.01,{ }^{t} p<0.001$ and ${ }^{\ddagger} p<0.0001$ shown on the column vs the To901317 alone treated condition by one-way ANOVA Dunnett's post hoc analysis, and values in the parenthesis under the graph show $p$ values of one-way ANOVA test. The significant difference between the control and To901317 alone was analyzed by unpaired Student's $t$ test.
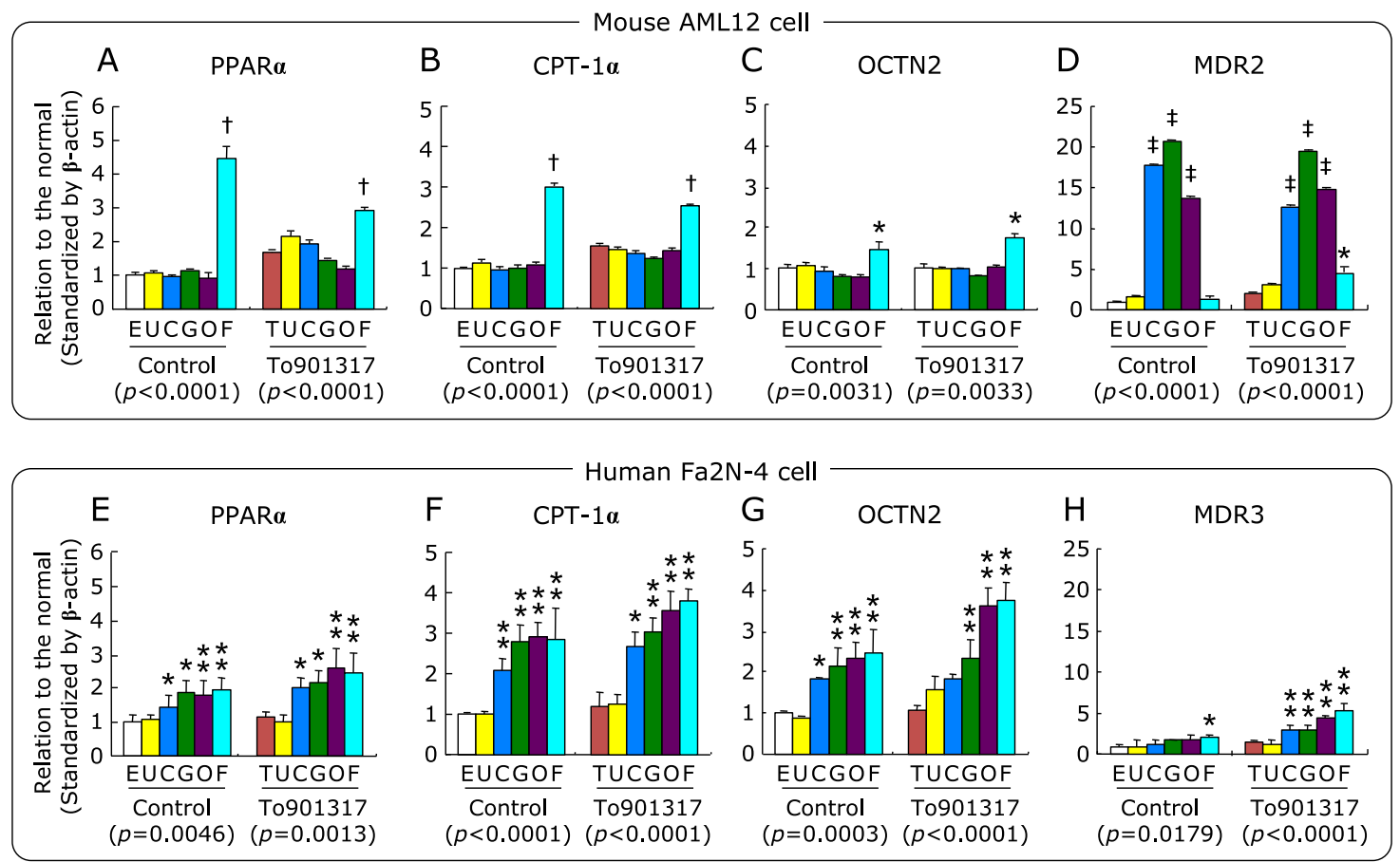

$\square$ E: EtOH alone as control $\square$ T: To901317 alone $\square$ U: UDCA $\square$ C: CDCA $\square$ G: GW4064 $\square$ o: OCA $\square$ F: FA

Fig. 7. The mRNA levels of lipolytic-related genes; PPAR $\alpha(A, E), C P T-1 \alpha(B, F)$, OCTN2 (C, G), and MDR2/3 (D, H), in AML12 and Fa2N-4 cells treated with FXR-ligands and To901317. The mRNA levels were measured by quantitative real-time PCR, standardized by $\beta$-actin, and expressed as relative to control condition. Data are shown as the mean \pm SD. ${ }^{*} p<0.05,{ }^{*} p<0.01,{ }^{\dagger} p<0.001,{ }^{\ddagger} p<0.0001$ vs the control condition by one-way ANOVA Bonferroni's post hoc analysis, and values in the parenthesis under graph show $p$ values of one-way ANOVA test. 


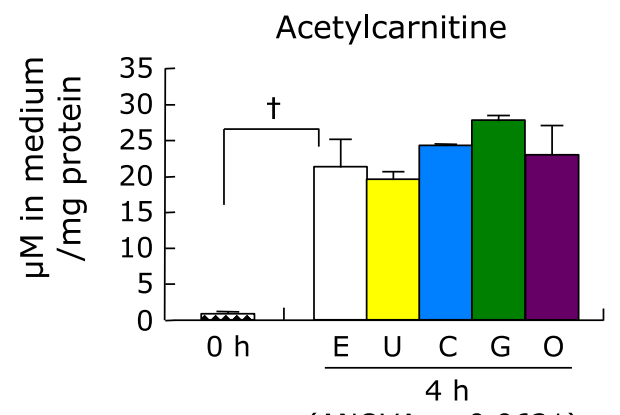

(ANOVA $p=0.0621$ )

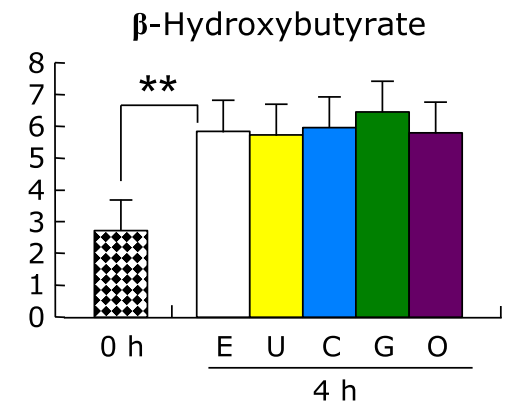

(ANOVA $p=0.1043$ )

B Human Fa2N-4 cell

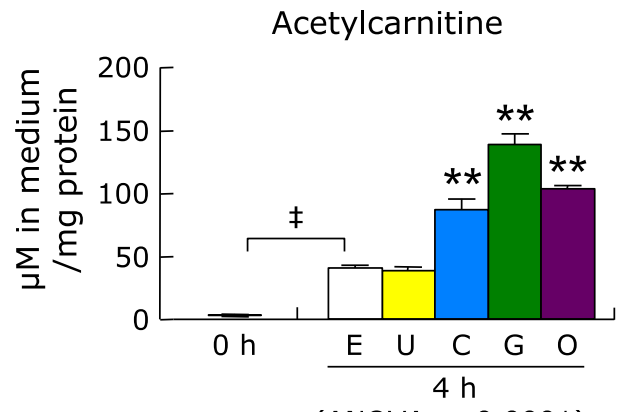

(ANOVA $p<0.0001$ )

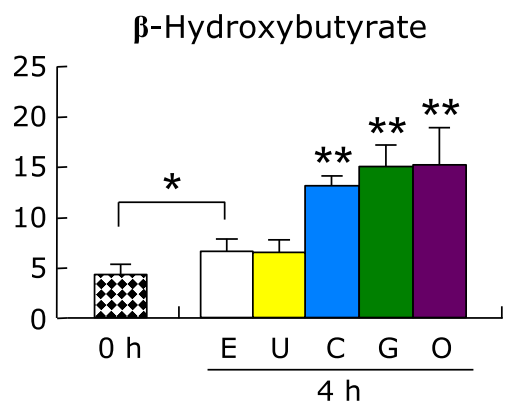

(ANOVA $p<0.0001$ )

$\mathrm{E}: \mathrm{EtOH}$ alone as control

U: UDCA

C: CDCA

G: GW4064

O: OCA

Fig. 8. Acetylcarnitine and BHB concentrations in medium after culture cells with the natural PPAR $\alpha$-ligand fatty acid and the natural and synthetic FXR-ligands. AML12 and Fa2N-4 cells were incubated in the medium containing $200 \mu \mathrm{M}$ palmitic acid, $1 \mathrm{mM}$ carnitine, and FXR-ligand (UDCA, CDCA, GW4064, or OCA) or PPAR $\alpha$-ligand (FA) for $4 \mathrm{~h}$, and then, the acetylcarnitine and BHB in the culture medium were measured by the LC-ESI-MS/MS system. Data are shown as the mean \pm SD. ${ }^{*} p<0.05,{ }^{*} p<0.01,{ }^{\dagger} p<0.001,{ }^{\ddagger} p<0.0001$ with the bar show significant differences between the $0 \mathrm{~h}$ and the control condition without the nuclear receptor ligands was calculated by unpaired Student's $t$ test. ${ }^{*} p<0.01$ on the column shows the significant difference compared with the control by one-way ANOVA post hoc Bonferroni's multiple test.

has been used as a dissolving agent for gallstone, emollients for biliary pain, and for acute cholecystitis, ${ }^{(50)}$ and as a for cholestasis, including PBC. ${ }^{(51)}$ Although UDCA has low cytotoxicity due to its higher hydrophilicity, it does not play a role as an FXRligand. ${ }^{(47-49)}$ Based on the results in the present and previous studies, CDCA would be a candidate therapeutic agent for fatty liver as a natural FXR-ligand. CDCA has been used as therapy to dissolve cholesterol-rich gallstones, ${ }^{(52,53)}$ and the effects of CDCA treatment on lowering plasma TG levels were actually reported in patients with gallstones ${ }^{(53)}$ and with primary hypertriglyceridemia. ${ }^{(54-56)}$ However, higher doses of CDCA may cause some side effects, including liver damage and diarrhea due to hydrophobic toxicity. Indeed, the present study showed that the higher doses of CDCA, but not that of UDCA, caused cell damage in both human and mouse cultured cells. Therefore, it is likely that CDCA is unsuitable as a therapeutic agent for fatty liver.

On the other hand, the synthetic FXR ligand, OCA, did not cause serious adverse events except for pruritis in clinical phase I and II studies. ${ }^{(14-18,57)}$ OCA has a higher affinity than CDCA for the ligand-binding domain of FXR. ${ }^{(7)}$ Furthermore, OCA has been shown to have enterohepatic circulation. It is absorbed by the intestine and secreted into the bile after conjugations with either taurine in rodents or glycine in humans, and consequently, dramatically alter the composition of the bile acid pool by the reducing the levels of primary bile acids (choric acid and CDCA). ${ }^{(14)}$ The influence of reduced primary bile acids as endogenous FXRligands in the bile acid pool is unclear, but OCA administration has a benefit to reduce the strong cytotoxic CDCA content. In the present study, GW4064 also had an excellent activity as an FXR-ligand for improvement of fatty liver. However, there is concern that GW4064 has potential toxicity and uncertain bioavailability in humans, ${ }^{(7,58)}$ and therefore, it has not been tested clinically.

In conclusion, FXR-activation using either natural or synthetic ligands improved fatty liver in cultured human cells by both the decreased synthesis and increased degradation of fatty acids through human-specific dual mechanisms involving both the FXR-SHP-SREBP-1c cascade and the FXR-PPAR $\alpha$ pathway. Because the natural FXR-ligand CDCA has a high potential to induce cellular damage, synthetic FXR-ligands, especially OCA, have already been evaluated in clinical trials and would be useful therapeutic agents as an early treatment for fatty liver.

\section{Author Contributions}

Conceptualization, TM and $\mathrm{AH}$; formal analysis, TM; investigation, TM and TI (3rd author); project administration, AH and TI (3rd author); resources, TI (4th author); supervision, YM; writing - original draft, TM; writing - review \& editing, AH.

\section{Acknowledgments}

Authors grateful thank to Professor Dr. Reberto Pelliciari, Department of Pharmaceurical Sciences, University of Bologna, 
Mouse AML12 cell
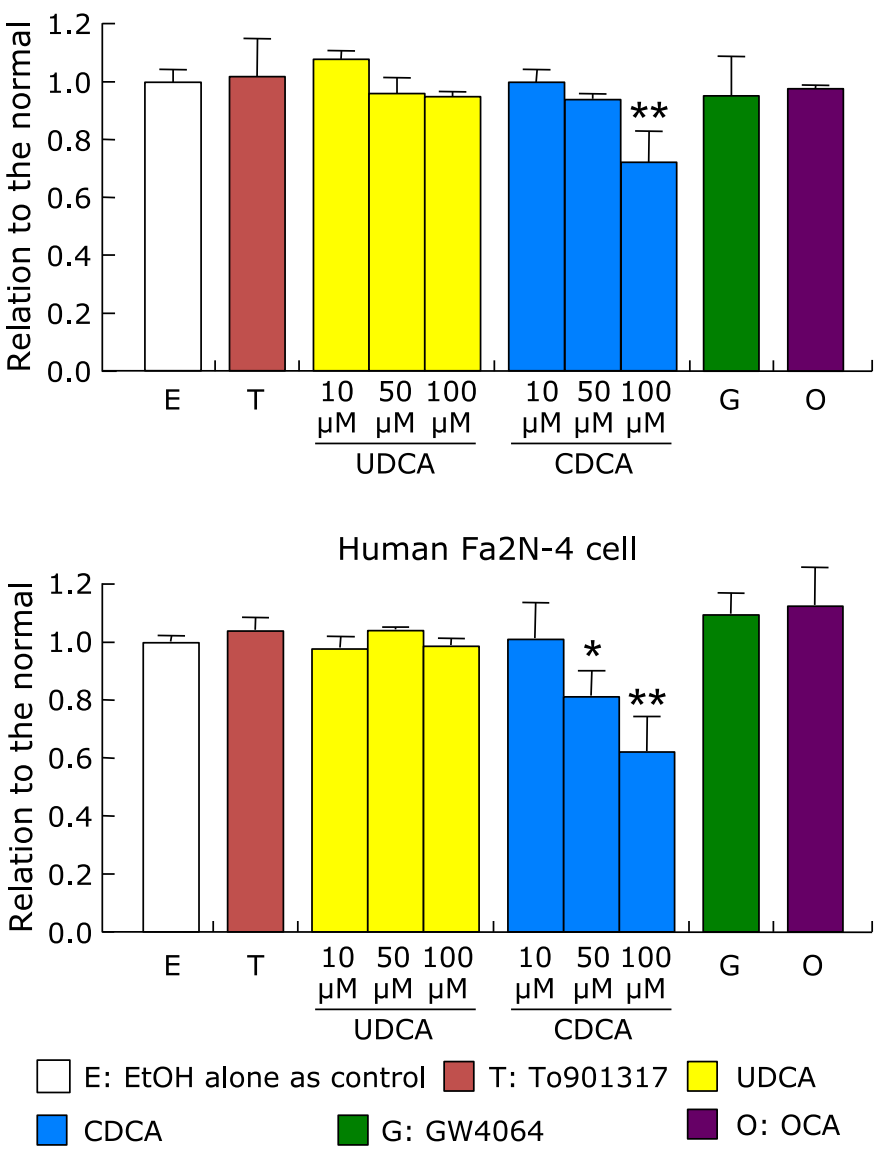

Fig. 9. Cell viability of AML12 and Fa2N-4 cells treated with $1 \mu \mathrm{M}$ To901317, $1 \mu \mathrm{M}$ GW4064, $1 \mu \mathrm{M}$ OCA, 10-100 $\mu \mathrm{M}$ UDCA or 10-100 $\mu \mathrm{M}$ CDCA for $24 \mathrm{~h}$. Cell viability was measured by the MTT assay, and expressed as relative to the control condition without the nuclear receptor ligands. Data are shown as the mean \pm SD. Statistical analysis was analyzed by one-way ANOVA Bonferroni's post hoc test. ${ }^{*} p<0.05$, $* * p<0.001$, vs the control. One-way ANOVA $p$ value: $p=0.0019$ in AML12 cells, $p=0.0032$ in Fa2N-4 cells.

\section{References}

1 Cohen JC, Horton JD, Hobbs HH. Human fatty liver disease: old questions and new insights. Science 2011; 332: 1519-1523.

2 Joseph SB, Castrillo A, Laffitte BA, Mangelsdorf DJ, Tontonoz P. Reciprocal regulation of inflammation and lipid metabolism by liver $\mathrm{X}$ receptors. Nat Med 2003; 9: 213-219.

3 DeBose-Boyd RA, Ou J, Goldstein JL, Brown MS. Expression of sterol regulatory element-binding protein 1c (SREBP-1c) mRNA in rat hepatoma cells requires endogenous LXR ligands. Proc Natl Acad Sci U S A 2001; 98: 1477-1482.

4 Janowski BA, Grogan MJ, Jones SA, et al. Structural requirements of ligands for the oxysterol liver X receptors LXR $\alpha$ and LXR $\beta$. Proc Natl Acad Sci USA 1999; 96: 266-271.

5 Goodwin B, Watson MA, Kim H, Miao J, Kemper JK, Kliewer SA. Differential regulation of rat and human CYP7A1 by the nuclear oxysterol receptor liver X receptor- $\alpha$. Mol Endocrinol 2003; 17: 386-394.

6 Watanabe M, Houten SM, Wang L, et al. Bile acids lower triglyceride levels via a pathway involving FXR, SHP, and SREBP-1c. J Clin Invest 2004; 113: 1408-1418

7 Modica S, Gadaleta RM, Moschetta A. Deciphering the nuclear bile acid receptor FXR paradigm. Nucl Recept Signal 2010; 8: e005.

8 Fiorucci S, Antonelli E, Rizzo G, et al. The nuclear receptor SHP mediates inhibition of hepatic stellate cells by FXR and protects against liver fibrosis.
Italy, and Professor Dr. Alan Hofmann, Department of Medicine, University of California, for kindly gift of OCA. Fenofibric acid used in this study was supplied by ASKA Pharmaceutical. Co., Ltd.

\section{Abbreviations}

ACC-1 acetyl-CoA carboxylase-1

$4 \beta$-HC 4 $\quad$-hydroxycholesterol

BHB $\quad \beta$-hydroxybutyrate

BSA bovine serum albumin

CDCA chenodeoxychoric acid

CPT-I $\alpha$ carnitine palomitoyltransferase-I $\alpha$

DMEM Dulbecco's modified Eagle's medium

DMEM/F12 Ham's F12 medium

ESI electrospray ionization

FA fenofibric acid

FAS fatty acid synthase

FBS fetal bovine serum

FXR farnesoid $X$ receptor

25-HC 25-hydroxycholesterol

ITS insulin-transferrin-selenium-X

$\mathrm{LXR} \alpha \quad$ liver $\mathrm{X}$ receptor- $\alpha$

MDR multidrug resistance protein

NAFLD nonalcoholic fatty liver disease

NASH non-alcoholic steatohepatitis

OCA obeticholic acid

OCTN2 organic cation transporter 2

PBC primary biliary cholangitis

$\operatorname{PPAR} \alpha \quad$ peroxisome proliferator-activated receptor- $\alpha$

22R-HC 22R-hydroxycholesterol

SCD-1 steatoryl-CoA desaturase-1

24S,25-EC 24S,25-epoxycholesterol

SHP small heterodimer partner

SREBP-1c sterol regulatory element binding protein-1c

TG

UDCA ursodeoxycholic acid

\section{Funding}

This research received no external funding.

\section{Conflict of Interest}

No potential conflicts of interest were disclosed.

Gastroenterology 2004; 127: 1497-1512.

9 Wang YD, Chen WD, Wang M, Yu D, Forman BM, Huang W. Farnesoid X receptor antagonizes nuclear factor kappaB in hepatic inflammatory response. Hepatology 2008; 48: 1632-1643.

10 Vanwijngaerden YM, Wauters J, Langouche L, et al. Critical illness evokes elevated circulating bile acids related to altered hepatic transporter and nuclear receptor expression. Hepatology 2011; 54: 1741-1752.

11 Gadaleta RM, van Erpecum KJ, Oldenburg B, et al. Farnesoid X receptor activation inhibits inflammation and preserves the intestinal barrier in inflammatory bowel disease. Gut 2011; 60: 463-472.

12 Pellicciari R, Costantino G, Camaioni E, et al. Bile acid derivatives as ligands of the farnesoid $\mathrm{X}$ receptor. Synthesis, evaluation, and structureactivity relationship of a series of body and side chain modified analogues of chenodeoxycholic acid. J Med Chem 2004; 47: 4559-4569.

13 Pellicciari R, Fiorucci S, Camaioni E, et al. $6 \alpha$-ethyl-chenodeoxycholic acid (6-ECDCA), a potent and selective FXR agonist endowed with anticholestatic activity. J Med Chem 2002; 45: 3569-3572.

14 Fiorucci S, Cipriani S, Mencarelli A, Baldelli F, Bifulco G, Zampella A. Farnesoid $\mathrm{X}$ receptor agonist for the treatment of liver and metabolic disorders: focus on 6-ethyl-CDCA. Mini Rev Med Chem 2011; 11: 753-762.

15 Mudaliar S, Henry RR, Sanyal AJ, et al. Efficacy and safety of the farnesoid $\mathrm{X}$ receptor agonist obeticholic acid in patients with type 2 diabetes and nonal- 
coholic fatty liver disease. Gastroenterology 2013; 145: 574-582.

16 Intercept Pharmaceuticals Inc. Press release 16 Mar 2014. Intercept announces positive pivotal Phase 3 POISE trial results. http://ir.interceptpharma.com/ news-releases/news-release-details/intercept-announces-positive-pivotalphase-3-poise-trial-results. Accessed 27 Sep 2018.

17 Intercept Pharmaceuticals Inc. Press release 12 Jan 2014. Intercept reports additional details about FLINT trial provided by NIDDK. http://ir.interceptpharma. com/news-releases/news-release-details/intercept-reports-additional-detailsabout-flint-trial-provided. Accessed 27 Sep 2018.

18 Adorini L, Pruzanski M, Shapiro D. Farnesoid X receptor targeting to treat nonalcoholic steatohepatitis. Drug Discov Today 2012; 17: 988-997.

19 Neuschwander-Tetri BA, Loomba R, Sanyal AJ, et al. Farnesoid X nuclear receptor ligand obeticholic acid for non-cirrhotic, non-alcoholic steatohepatitis (FLINT): a multicentre, randomised, placebo-controlled trial. Lancet 2015; 385: 956-965.

20 Cipriani S, Mencarelli A, Palladino G, Fiorucci S. FXR activation reverses insulin resistance and lipid abnormalities and protects against liver steatosis in Zucker (falfa) obese rats. J Lipid Res 2010; 51: 771-784.

21 Mencarelli A, Renga B, Distrutti E, Fiorucci S. Antiatherosclerotic effect of farnesoid X receptor. Am J Physiol Heart Circ Physiol 2009; 296: H272H281.

22 Evans MJ, Mahaney PE, Borges-Marcucci L, et al. A synthetic farnesoid X receptor (FXR) agonist promotes cholesterol lowering in models of dyslipidemia. Am J Physiol Gastrointest Liver Physiol 2009; 296: G543-G552.

23 Cariou B, van Harmelen K, Duran-Sandoval D, et al. The farnesoid X receptor modulates adiposity and peripheral insulin sensitivity in mice. $J$ Biol Chem 2006; 281: 11039-11049.

24 Maloney PR, Parks DJ, Haffner CD, et al. Identification of a chemical tool for the orphan nuclear receptor FXR. J Med Chem 2000; 43: 2971-2974.

25 Liu H, Zhong H, Leng L, Jiang Z. Effects of soy isoflavone on hepatic steatosis in high fat-induced rats. J Clin Biochem Nutr 2017; 61: 85-90.

26 Desvergne B, Wahli W. Peroxisome proliferator-activated receptors: nuclear control of metabolism. Endocr Rev 1999; 20: 649-688.

27 Lee $\mathrm{CH}$, Olson P, Evans RM. Minireview: lipid metabolism, metabolic diseases, and peroxisome proliferator-activated receptors. Endocrinology 2003; 144: 2201-2207.

28 Pineda Torra I, Claudel T, Duval C, Kosykh V, Fruchart JC, Staels B. Bile acids induce the expression of the human peroxisome proliferator-activated receptor $\alpha$ gene via activation of the farnesoid $\mathrm{X}$ receptor. Mol Endocrinol 2003; 17: 259-272.

29 Davidson BC, Giangregorio A, Girao LA. The influence of fatty acids on normal and transformed human liver cells in culture. Anticancer Res 1998; 18: 3533-3538.

30 Joshi-Barve S, Barve SS, Amancherla K, et al. Palmitic acid induces production of proinflammatory cytokine interleukin- 8 from hepatocytes. Hepatology 2007; 46: 823-830.

31 Honda A, Yoshida T, Tanaka N, et al. Increased bile acid concentration in liver tissue with cholesterol gallstone disease. J Gastroenterol 1995; 30: 61-66.

32 Schultz JR, Tu H, Luk A, et al. Role of LXRs in control of lipogenesis. Genes Dev 2000; 14: 2831-2838.

33 Wu JC, Merlino G, Fausto N. Establishment and characterization of differentiated, nontransformed hepatocyte cell lines derived from mice transgenic for transforming growth factor alpha. Proc Natl Acad Sci U S A 1994; 91: 674678.

34 Mills JB, Rose KA, Sadagopan N, Sahi J, de Morais SM. Induction of drug metabolism enzymes and MDR1 using a novel human hepatocyte cell line. $J$ Pharmacol Exp Ther 2004; 309: 303-309.

35 Liu Z, Mutlib AE, Wang J, Talaat RE. Liquid chromatography/mass spectrometry determination of endogenous plasma acetyl and palmitoyl carnitines as potential biomarkers of beta-oxidation in mice. Rapid Commun Mass Spectrom 2008; 22: 3434-3442.

36 Miyazaki T, Honda A, Ikegami T, et al. Simultaneous quantification of salivary 3-hydroxybutyrate, 3-hydroxyisobutyrate, 3-hydroxy-3-methylbutyrate, and 2-hydroxybutyrate as possible markers of amino acid and fatty acid catabolic pathways by LC-ESI-MS/MS. Springerplus 2015; 4: 494.

37 Miyamoto Y, Miyazaki T, Honda A, Shimohata H, Hirayama K, Kobayashi M. Retention of acetylcarnitine in chronic kidney disease causes insulin resistance in skeletal muscle. J Clin Biochem Nutr 2016; 59: 199-206.

38 Ghoshal AK, Guo T, Soukhova N, Soldin SJ. Rapid measurement of plasma acylcarnitines by liquid chromatography-tandem mass spectrometry without derivatization. Clin Chim Acta 2005; 358: 104-112.

39 Denizot F, Lang R. Rapid colorimetric assay for cell growth and survival. Modifications to the tetrazolium dye procedure giving improved sensitivity and reliability. J Immunol Methods 1986; 89: 271-277.

40 Takahashi Y, Soejima Y, Fukusato T. Animal models of nonalcoholic fatty liver disease/nonalcoholic steatohepatitis. World J Gastroenterol 2012; 18: 2300-2308.

41 van Vlies N, Ferdinandusse S, Turkenburg M, Wanders RJ, Vaz FM. PPAR $\alpha$-activation results in enhanced carnitine biosynthesis and OCTN2mediated hepatic carnitine accumulation. Biochim Biophys Acta 2007; 1767: 1134-1142.

42 Kok T, Bloks VW, Wolters H, et al. Peroxisome proliferator-activated receptor alpha (PPARalpha)-mediated regulation of multidrug resistance 2 (Mdr2) expression and function in mice. Biochem J 2003; 369 (Pt 3): 539-547.

43 Calkin AC, Tontonoz P. Transcriptional integration of metabolism by the nuclear sterol-activated receptors LXR and FXR. Nat Rev Mol Cell Biol 2012; 13: $213-224$.

44 Huang L, Zhao A, Lew JL, et al. Farnesoid X receptor activates transcription of the phospholipid pump MDR3. J Biol Chem 2003; 278: 51085-51090.

45 Honda A, Ikegami T, Nakamuta M, et al. Anticholestatic effects of bezafibrate in patients with primary biliary cirrhosis treated with ursodeoxycholic acid. Hepatology 2013; 57: 1931-1941.

46 Liu Y, Binz J, Numerick MJ, et al. Hepatoprotection by the farnesoid X receptor agonist GW4064 in rat models of intra- and extrahepatic cholestasis $J$ Clin Invest 2003; 112: 1678-1687.

47 Parks DJ, Blanchard SG, Bledsoe RK, et al. Bile acids: natural ligands for an orphan nuclear receptor. Science 1999; 284: 1365-1368.

48 Makishima M, Okamoto AY, Repa JJ, et al. Identification of a nuclear receptor for bile acids. Science 1999; 284: 1362-1365.

49 Wang H, Chen J, Hollister K, Sowers LC, Forman BM. Endogenous bile acids are ligands for the nuclear receptor FXR/BAR. Mol Cell 1999; 3: 543553.

50 Tomida S, Abei M, Yamaguchi T, et al. Long-term ursodeoxycholic acid therapy is associated with reduced risk of biliary pain and acute cholecystitis in patients with gallbladder stones: a cohort analysis. Hepatology 1999; 30: 6-13.

51 Ikegami T, Matsuzaki Y. Ursodeoxycholic acid: mechanism of action and novel clinical applications. Hepatol Res 2008; 38: 123-131.

52 Thistle JL, Hofmann AF. Efficacy and specificity of chenodeoxycholic acid therapy for dissolving gallstones. $N$ Engl J Med 1973; 289: 655-659.

53 Iser JH, Sali A. Chenodeoxycholic acid: a review of its pharmacological properties and therapeutic use. Drugs 1981; 21: 90-119.

54 Carulli N, Ponz de Leon M, Podda M, et al. Chenodeoxycholic acid and ursodeoxycholic acid effects in endogenous hypertriglyceridemias. A controlled double-blind trial. J Clin Pharmacol 1981; 21: 436-442.

55 Camarri E, Fici F, Marcolongo R. Influence of chenodeoxycholic acid on serum triglycerides in patients with primary hypertriglyceridemia. Int J Clin Pharmacol Biopharm 1978; 16: 523-526.

56 Bateson MC, Maclean D, Evans JR, Bouchier IA. Chenodeoxycholic acid therapy for hypertriglyceridaemia in men. Br J Clin Pharmacol 1978; 5: 249 254.

57 Sanyal AJ, Campbell-Sargent C, Mirshahi F, et al. Nonalcoholic steatohepatitis: association of insulin resistance and mitochondrial abnormalities. Gastroenterology 2001; 120: 1183-1192.

58 Fiorucci S, Mencarelli A, Palladino G, Cipriani S. Bile-acid-activated receptors: targeting TGR5 and farnesoid-X-receptor in lipid and glucose disorders. Trends Pharmacol Sci 2009; 30: 570-580. 